\title{
Reply to the letter written by Mayeen Uddin Khandaker on: "Distribution and assessment of radionuclides in sediments, soil and water from the lower basin of river Pra in the Central and Western Regions of Ghana” (DOI 10.1007/s10967-014-3637-5)
}

\author{
O. K. Adukpo ${ }^{1}$ - A. Faanu ${ }^{1}$ - H. Lawluvi ${ }^{1}$ L. Tettey-Larbi ${ }^{1}$. G. Emi-Reynolds ${ }^{1}$ \\ E. O. Darko ${ }^{1}$ C. Kansaana ${ }^{1}$ - D. O. Kpeglo ${ }^{1}$ - A. R. Awudu ${ }^{1}$ E. T. Glover ${ }^{2}$ • \\ P. A. Amoah ${ }^{1}$ A. O. Efa $^{1} \cdot$ L. A. Agyemang ${ }^{1}$ B. K. Agyeman ${ }^{1} \cdot$ R. Kpordzro ${ }^{1}$. \\ A. I. Doe ${ }^{1}$
}

Received: 1 April 2015/Published online: 28 April 2015

(C) Akadémiai Kiadó, Budapest, Hungary 2015

\section{Dear Editor-in-Chief,}

We appreciate the letter written by Dr. M. U. Khandaker, drawing our attention to some aspects in our publication he thought needed to be addressed. We however disagreed with most of the issues he raised and our responses are as follows:

1. He thought the minimum detectable activity (MDA) value for $K$ is too low, the counting time was too short based on his experience and why distilled water was used. First of all the distilled water was used to limit the level of backscatter radiation within the detector system during the background count. Also, we want to state that a low background spectrometry system was used for the counting. In other to optimize the result of the background count and the real samples, the same counting time was used. We agree that the longer the counting time the greater the peak area, however, based on the prevailing laboratory condition which could not enable us to consider a longer counting time 36,000 was used which could also give an appreciable count rate.

O. K. Adukpo

oscadukpo@yahoo.com

1 Environmental Protection and Waste Management Centre, Radiation Protection Institute, Ghana Atomic Energy Commission, P.O. Box LG 80, Legon, Accra, Ghana

2 National Radioactive Waste Management Centre, National Nuclear Research Institute, Ghana Atomic Energy Commission, P.O. Box LG 80, Legon, Accra, Ghana
The MDA is defined as the smallest quantity of radioactivity that could be measured under specified conditions, and is another factor which is an important concept in environmental level measurement. The MDA depends on the lower limit of detection (LLD) and the counting efficiency of a counting system. The MDA is very important, particularly in environmental level systems, where the count rate of a sample is almost the same as the count rate of the background. The MDA was calculated using the conventional MDA method based on statistical convergence of $95 \%$ confidence level. The value obtained for $K$ was based on experimental data and calculation done using the conventional method.

2. We also want to state that the equation used in calculating the activity is correct.

It is true that the delay time is far less than half-live of the radionuclide of interest, thus

For $t_{d} \ll \ll T_{\frac{1}{2}}$ of parent nuclide

$\lambda_{p} t_{d} \cong 0$

Hence, $\quad e^{0}=1$

where all symbols have their usual meanings.

Then it accurate to calculate activity concentration of a radionuclide using the equation since we were interested in activity at the time of sampling, in other to determine the parent radionuclide taking into consideration attainment of secular equilibrium.

3. His third point has been addressed in point 2 .

4. The counting has been addressed in point 1 .

Based on our explanation, we believed Dr. M. U. Khandaker will appreciate the results of this work and withdraw his call for an erratum. 